\title{
Beyond epistemology and freedom: A deliberative democratic model to promote popular participation
}

\author{
Más allá de la epistemología y la libertad: un modelo de democracia \\ deliberativa para promover la participación popular
}

\author{
OSVALDO GONZÁLEZ-REYES
}

Universidad Autónoma de Madrid

\section{Cómo citar/Citation}

González-Reyes, O. (2021). Beyond epistemology and freedom: A deliberative democratic model to promote popular participation. Revista Española de Ciencia Política, 56, 123-144. Doi: https://doi.org/10.21308/recp.56.05

\begin{abstract}
This article thoroughly analyzes one of the major problems of current democracies, the balance between epistemic benefits and individual freedom. We dive into this debate departing from the various criticisms that have been historically made against democracy and presenting deliberative democracy as an alternative. Within the long deliberative democratic debate, several authors such as Christiano Mansbridge or Hélène Landemore have proposed views that fail to meet the logical and participatory standards expected from a democratic system. We carry out an analysis on these proposals reflecting on their weak points and consequences. In addition, we link these views to the discussion about the role citizens should play in any democratic system. It is concluded that the most common view held about democracy, the epistemic centred one, overlooks basic rights inherent to any individual and undermines the ability of a population to jointly thrive and develop its culture. This is the reason why we propose a flexible model where any group of citizens has substantial equality of opportunities to propose alternatives to the current norms and laws and convince the majority of the population to change them. This model has been mainly focused on the interactions between individuals and state institutions.
\end{abstract}

Keywords: deliberative, democracy, epistemic, freedom, participation.

\section{Resumen}

En este artículo se analiza en profundidad uno de los principales problemas relacionados con las democracias actuales: el equilibrio entre beneficios epistémicos y libertad individual. 
Profundizamos en este debate partiendo de las diversas críticas que históricamente se han planteado contra la democracia y presentando la democracia deliberativa como alternativa. Dentro del extenso debate democrático deliberativo, varios autores como Christiano Mansbridge o Hélène Landemore han propuesto puntos de vista que no cumplen con los estándares lógicos y participativos que se esperan de un sistema democrático. Realizamos un análisis de estas propuestas reflexionando sobre sus puntos débiles y consecuencias. Además, vinculamos estos puntos de vista a la discusión sobre el papel que los ciudadanos deberían jugar en cualquier sistema democrático. Concluimos que la perspectiva epistémica, la más común en la democracia deliberativa, pasa por alto los derechos básicos inherentes a cualquier individuo y socava la capacidad de una población de prosperar y desarrollar su cultura de manera conjunta. Por ello, proponemos un modelo flexible donde cualquier conjunto de ciudadanos tenga una sustancial igualdad de oportunidades para proponer alternativas a las normas vigentes y convencer a la mayoría de la población de modificarlas. Este modelo se centra principalmente en las interacciones entre los individuos y las instituciones estatales.

Palabras clave: deliberativo, democracia, epistémico, libertad, participación.

\section{INTRODUCTION}

Democratic systems receive constant criticism from different angles. There are three fundamental complaints about democracy that seem well-founded at first sight. Firstly, democracy is ineffective to resolve citizens' problems; secondly, having a democratic system only serves to divide public opinion and polarise society; and thirdly, democracy is not a legitimate system because it underrepresents the people's will, especially minority opinions. In fact, all these complaints come from the common premise that "the democratic system is unable to identify and enact citizens' demands". Consequently, it is claimed that not every decision made in a democratic system is a legitimate one.

Since antiquity, different societies have come up with different solutions to counteract this claim. One of the most ancient forms of democratic system is direct democracy whose classic example was the Athenian democracy. Historically, it consisted in the complete participation of those with the right to vote in a sort of general assembly (Kobach, 1993). Another more modern solution is representative democracy. In this kind of system, the citizens do not participate directly in the process of law making, but they elect representatives that are supposed to legislate based on citizens' interests. In some cases, this system even incorporates direct democracy initiatives directly from the citizens. However, in most cases citizens vote for political parties rather than choosing individual representatives.

However, none of these systems has been able to properly respond to the previous criticisms. We understand the "quality of democracy" as the capability of a democratic system to identify the changing needs of its citizenry and adapt its policies to them. A minimum requirement for democratic self-determination is that citizens, if 
they wish, could have access to debates at any political level, either by themselves or by the intervention of interest groups. Furthermore, it is not only the task of the state to actively involve its citizens in the political sphere by giving them tools to assess their own circumstances, but it must also be able to institutionalise dissent in a constructive way with practical consequences (Red de Conocimientos Electorales, n. d.). On many occasions, representative democracy per se is not able to produce these conditions. For example, in Latin America, the lack of these aspects has led to poor socioeconomic development and the emergence of violence that do not only threat individuals' security but also the very existence of the state and its sovereignty to exercise the rule of law (Morlino, 2014).

Deliberative democracy is a term that was born during the 1980 's, thanks to the works by Dryzek and Habermas; however, it did not gain full attention until the 1990's (Dryzek, 2000; Habermas, 1996). This theoretical movement objects that current democratic systems do not include a proper deliberation of ideas. Therefore, it considers public deliberation as an essential component of the democratic process that must expose everyone's views and determine the aims to be achieved later by the political institutions. Given these characteristics, we can see how theories of deliberative democracy could respond to the previous criticisms. In this case, democracy would represent citizens' different perspectives and effectively resolve people's real problems by means of deliberation. Nevertheless, deliberative democracy is not infallible. For example, in many cases it is difficult to define how the decision-making process would function. In addition, the sharp division that deliberative democracy assumes between deliberation and bargaining is not clear in real cases, since both, bargaining and deliberation can have a cooperative dimension. In this article I will focus on a particular conception of deliberative democracy, the epistemic view, and its characteristics. Specifically, I will analyze several objections to its claims, related to the role of social influence, unanimous consensus and the value of dissent.

The epistemic view of deliberative democracy argues that the power of deliberative democracy rests -compared to other systems- on the fact that deliberation provides broader knowledge about an issue and helps participants make the "best" possible decision. My aim is to show that there is a different view of deliberative democracy that is not merely based on an epistemic justification but also on moral rights. I will attempt to demonstrate that making practical choices is a necessary characteristic of any political system; but that it cannot be achieved by violating the right of self-determination. In fact, it might be possible that more epistemic benefits can be obtained from a deliberative democratic system if both aspects are included.

The article is divided into four main parts. First, I will explain the conditions for deliberative democracy as well as some of its characteristics. Second, I will discuss the epistemic conception of deliberative democracy. Third, I will offer a critical reflection about its claims. Finally, on the basis of this reflection I will offer an alternative deliberative democratic system that relies on both, epistemic benefits and freedom. 


\section{DELIBERATIVE DEMOCRACY: CONDITIONS AND CHARACTERISTICS}

Defining "deliberative democracy" is difficult since it comprises a variety of complex concepts. However, we can distinguish several aspects common to many deliberative democratic theories (Bächtiger et al., 2018: 1-25). First, deliberative democracy is a form of democracy that emphasises the role of deliberation in collective decision-making. Any collective decision must be preceded by deliberation. The meaning that deliberation acquires in this context is the activity of proposing and weighing of arguments for and against a given view based on certain standards -i.e. rationality. Second, there must be equality of participation which, in this sense, refers to direct argumentation and coalition building among participants.

Hence, deliberative democracy can be understood as a democratic system based on certain principles. First, deliberation is central to decision-making. Second, deliberation is supposed to be a rational process, not a defence of personal interests and, it is based on the participants' respect for opposing views and the use of evidence-based reasons. This way, deliberation ensures the conditions for impartiality and a more informed formation of opinions. Nevertheless, as we will see, different definitions of deliberation have been proposed in current debates.

According to Fishkin and Luskin (2005), any kind of deliberative democracy should also incorporate the following characteristics: The participants are given full access to accurate information that they believe is relevant for the issue. There is a diversity of perspectives represented in the discussion. The arguments given from one perspective are compared to those offered from other perspectives. Finally, participants consider all the arguments in a truthful way.

The term deliberative democracy started being used by Joseph Bessette in the 1980 's with the aim of improving the quality of democracy (Bessette, 1994). He and other authors like Dryzek (2000) had denounced that debates in contemporary democracies were generally superficial, that elites tried to second-guess what their electorates liked and that decisions were made by the aggregation of private preferences. They decided to focus on decision-making and proposed "the giving of defensible reasons in the debate" as the source of legitimacy. This way, legitimate decisions would be based on serious public debate instead of aggregation of preferences.

The most common conception of deliberative democracy has a rather strong rationalist character. This means that it is understood as a kind of scientific process where there are strict procedural conditions. However, as we will see in following sections, the current conception of deliberation includes other factors besides rationality. For example, it is sometimes understood as a pedagogic process, rather than a rational one, where there is dynamic opinion formation (Anderson, 2006)

As I previously mentioned, there are different views within the debate about deliberative democracy. First, there is a distinction between epistemic or instrumental views and non-instrumental ones. The epistemic or instrumental view justifies deliberative democracy by epistemic arguments. Following the definition by Estlund and 
Landemore (2018: 2), epistemic benefits mean achieving the best decision at the end of a deliberative process where the criterion to evaluate possible decisions is an epistemic one. In other words, the partisans of this view defend "the quality of democratic answers". On the other hand, the non-instrumental view justifies deliberative democracy by placing its value on other features that are inherently beneficial, such as the liberty or equality of those who participate.

Once these concepts have been clarified, I will focus on the epistemic view, and I will analyze its different claims and objections in order to reflect on whether deliberative democracy can be justified.

\section{AN EPISTEMIC JUSTIFICATION OF DELIBERATIVE DEMOCRACY}

In this section I will present the epistemic view of deliberative democracy. I will do this by discussing Landemore's argument in favor of lottocracy (ibid.). Finally, I will explain some objections against these claims; above all, those related to the need for unanimous consensus and random samples.

One of the most basic epistemic arguments in favor of deliberative democracy is linked to the sovereignty of a political system. Particularly, I will call it Eslund's authority claim that expresses the basic assumption that the political authority of any system relies on whether the system is expected to have some minimum epistemic benefits, which are "performing better than random" (ibid.: 3). Only if citizens perceive the system as acting better than random, they can consider it legitimate. In other words, the system is expected to achieve specific goals that are not led by randomness during the decision-making but by another procedure. Eslund hints that democracies generally fulfil this condition and that deliberation is specifically a "producer" of epistemic benefits (id.). As a result, this argument implies that the epistemic benefits would be the distinctive factor that would explain the success of democracies in the world.

A possible objection against this claim is that it seems to have overlooked an important aspect of the political sphere (id). Even though it is difficult to consider all the factors to make the right choice in any political system, most of the time both citizens and leaders can guess what actions are clearly better than random -i.e., a nuclear war between the Netherlands and the USA would not be a good idea. If leaders can perform better than random most of the time and regardless of the kind of political system, what would then be the difference between an authoritarian regime and a democratic one? Therefore, if "performing better than random" is not a sufficient factor to defend the success of democracy over other systems, the legitimacy of democracy must be based on something else.

Landemore follows the previous claim about epistemic benefits, but she focuses on a different perception (id.). Her idea is that intersubjective deliberation is better suited to arrive at the right solution than any other kind of mechanism because it is a process through which individuals explain their views and adapt them to better arguments 
proposed by others. This way, participants narrow down the options until they find the best one as the final decision.

Landemore (2017) assumes that there is a "self-revealing nature of the truth" that will be disclosed at the end of the deliberation process. In other words, that only one among all the views proposed as solutions during the deliberation is objectively closer to the truth. Deliberation is, thus, a process where different views are contrasted, and the right solution is found at the end of it. This "truth revealing" process is done in a sequence of steps. Firstly, the deliberation setting allows participants to expose their views on a matter. They propose different options and give reasons to support them. Secondly, each participant critically assesses the reasons in favor of every option from their own point of view. Given the current knowledge about the issue, the participants reject the weakest or least feasible perspectives and support the most "solid" or difficult ones to refute. Thirdly, in the process of discussing each other's arguments, every participant is supposed to reshape their own views based on the strength of arguments held by the others. This creates new solutions to the problem and puts them on the table. The new solutions go through the same process of debate and adaptation. In every new round of deliberation, the participants narrow down the options more and more in search for the most difficult one to refute. Finally, only one possible solution remains, and the participants accept it unanimously as the best one. As a result of this exchange of arguments, all the different views get narrowed down to one single option which gets considered the true solution to the problem. In addition, some authors such as Fishkin (2018: 27) have found some empirical support for this theory. During his investigation, participants debated different political initiatives in small groups and their opinions were measured before and after the deliberation. As a result, the public opinion about 8 out of 14 proposals changed and common consensus was achieved on the final decision.

Moreover, Landemore (2017) proposes an epistemic argument based on diversity that is the nucleus of the previous claim. This argument is called collective intelligence. Its main premise is that the more inclusive the deliberation process is, the more accurate the solution resulting from it will be. In her article, Landemore explains the whole process in two steps as follows: The first step is called the "Diversity Trumps Ability Theorem" and it is based on the assumption that more cognitively diverse people will come up with better solutions. She borrows this argument from Hong and Page (2004: 16388). Here, cognitive diversity means approaching a problem or a question in a different way. Different approaches to a problem include different aspects of reality that others are missing. Therefore, a more diverse group of decision makers would come up with more accurate solutions.

The second step links cognitive diversity to the size of the group. So far, she has only explained that cognitive diversity leads to a better choice, but why would cognitive diversity occurs only in big groups? Landemore calls this second step "Numbers Trump Ability Theorem" and argues that the easiest way to achieve cognitive diversity is by being as inclusive as possible; since current political problems are "complex" and "changing", it is better to count with as many perspectives as possible; just in case they are needed in different situations. 
Nevertheless, Landemore (2017) explains that there are certain restrictions for the optimum functioning of collective intelligence. First, cognitive diversity must be a kind of diversity regarding different perspectives on reality. She says that there cannot be a diversity of values or goals which would actually harm the collective effort, because the discussion could not be approached from the same standpoint and this would impede us from advancing towards a conclusion. An example of the latter could be a deliberative debate between people from an Amazonian tribe and a group of cosmopolitan Europeans; since they have different values and goals, they could not deliberate from the same standpoint. Second, the discussed topic must be difficult enough; this way we ensure that there is enough disagreement to produce diversity and therefore that the deliberation includes other parts of the reality that may be useful to find the right solution. Third, participants need to have a certain reasoning capability, they need to be able to compare different views, identify their feasibility and adapt their opinions depending on the given information. Fourth, it is convenient that participants have views as different from each other as possible, although in the end they will all agree when the right solution is "made evident" to them.

But where is the limit of inclusiveness? We could still add different views until we include the whole population, even though, in the end, people are supposed to agree on the same solution. This persuades Landemore (id.) to suggest that it is preferable to select a random sample of participants, since this still increases the chances of having very different views without having an unmanageable number of participants. A random selection of problem solvers still performs better than an expert panel. Consequently, at a political level, she supports small, direct, deliberative groups, or multiple democratic representative levels.

Landemore's solution is supposed to resolve several democratic problems at once. First, given that, face-to-face deliberation of high quality is incompatible with mass participation, lotteries would solve the problem of deliberative feasibility that traditionally undermines the epistemic virtues of maximal inclusion. But lotteries would also solve the problem of rational ignorance and rational irrationality since they imply a group of cognitively diverse people and this provides very different views that will allow each member to deliberate taking into account a complete perspective of reality.

Her claim to intersubjective deliberation and specifically to its supporting theory of cognitive diversity is not free from criticisms either. In fact, there are several objections made to this epistemic view that are worth discussing. The first objection regards social interaction among members of the deliberative process. This theory assumes that all members participate in a rational and homogeneous way when it comes to the amount of information they give or the way they receive and disclose the information coming from others. In other words, all participants are supposed to process the information in the same way during the deliberation. Otherwise, the system would be influenced by many collateral variables, such as the cognitive capability to understand messages or the ability to express thoughts, that would distort the common way of reasoning towards the "objective" solution. As a result, this way of processing the information leads the participants to unanimous consensus. Despite this assumption, 
it is well-known that members of any social group never interact homogeneously since there is always social influence. This implies that individuals have cognitive limitations and biases regarding the information exchange. For example, social pressure imposed by certain members of the group often leads other members to be silent or not to explain their arguments completely. In addition, some group members convey information to be used at another time, which leads others not to disclose what they know because they think it is irrelevant or risky information. These social factors can lead to the propagation of errors, cascade effects, and even group polarization. Therefore, they make very unlikely unanimous consensus within the deliberative body or even that an "objective" solution may be reached.

The second objection is directly linked to this previous one and revolves around unanimous consensus and random sampling. In the positivist way in which Landemore sees deliberative democracy, there is always one single ojective solution. This implies that people with different views will have to adapt their arguments to the "true" solution when they rationally discover that this is better than what they supported. Therefore, what seems to matter to Landemore is not that citizens find the rationality of the decision by themselves bringing something to the deliberation from their standpoints but that they simply accept the decision as the most rational one and adapt to it. Based on these assumptions, deliberative democracy would diminish a person's power to contribute to the democratic process for the sake of enhancing the supposed quality of decisions. Therefore, instead of contributing to the democratic process and influencing the final decision according to their views, citizens are only expected to accept a decision made by the deliberative body simply because it is the "best" one.

However, Landemore overlooks this aspect. She assumes that the adaptation of participants' views is done naturally following rationality and that there is no moral loss in the fact that we do not participate directly in the decision. On the contrary, every time that an individual must adapt their first choice to a "better" view there is some moral constraint since they will have to accommodate to a decision that is not their own. Indeed, an important value of deliberative democracy is the moral right to self-determination. If it is assumed that citizens will adopt the decision made by a deliberative body only because it is "more rational" than their owns we are violating this right in favor of imposing that decision homogeneously. Even if citizens' views are "irrational" in the eyes of the deliberative body, this does not mean that they are in the eyes of the citizens. Besides, why would they accept the "rationality" of a decision that has been made without even taking their own personal views into account? It would be difficult to deal with this aspect when arguing for "rationally binding" decisions that citizens must accept as a kind of unanimous consensus when they have not participated in the decision-making. "A morally desirable democracy -a radical democracy- needs critical an autonomous citizens, ready to judge the institutions and normative system in which they have been born and accept them only if they favor the development of their autonomy" (Cortina, 1993).

Definitely, unanimous consensus requires regulation of our own ideas based on the ideas of others. But this could be too restrictive to be plausible. In fact, it is not 
clear what the difference would be -regarding our decision power- between this system and any other system where participants live in a society that is regulated by principles they do not accept. As a result, why should we follow rational reasoning in decision-making and adapt to the "true" solution when this violates our right to self-determination?

This criticism is extended by the objection posed by Lafont (2019: 100-157). It is worth remembering here that Landemore (2017) advocates for a system where the lawmakers are chosen from a random sample of the population. Lafont (2019: 100-157) noticed that by reducing the epistemic argument to simply searching the "truth", the epistemic view stipulates away the justification of the decisions to the broader sectors of the population that do not participate in the deliberation but that are affected by the decisions. In fact, the "truth" is assumed to be obvious to everyone once it is found, however, a decision being "true" or "rational" does not guarantee a sufficient justification for individuals to accept it from their standpoints - even less when they have not participated in the decision-making. The main claim of Lafont (id.) is that democracy should not be about "guessing" the right answer to political questions since most current systems can already do this. The real purpose of democracy should be convincing other citizens that a certain decision also supports their interests, in other words, political decisions need to be justified to the whole political community that will be subjected to them. This way, it is possible to preserve the value of disagreement.

Any proposal that suggests unanimous consensus for epistemic benefits stipulates away the value of political disagreement. Even the cognitive diversity theory -the core of Landemore's view- assumes this stipulation. It explains that at the beginning of the deliberation the participants "may think very differently" but that after having deliberated the true solution is "made obvious to all of them". In short, participants are always "determined" to find the best solution since the beginning and once this solution has been found it is assumed that the rest of the population will follow in its acceptance. This kind of argument implies an absurd homogeneity between decision-makers and decision-takers "once decision-makers hit on the right political answers, agreement by decision-takers will simply follow" (ibid.: 98). This is especially a problem in Landemore's theory for one reason. After the decision has been made by the deliberative body it is taken as final for the whole citizenry, since she is focused on arriving at a "truth" common to everyone there is no room in her system for dissent after the decision has been made. She could not include justifications to social groups with different interests since this would mean that there is disagreement, and therefore that the solution is not objective at all. Indeed, this would lead to negotiations which would reject the system's basic idea that there is a rational decision in the first place. As a result, a system like this would look more similar to an epistocracy ruled by a group of a few "knowledgeable" people. It would make little difference if the participants of the deliberation are part of an elite or a random-selected sample since they would act the same way.

Furthermore, As I previously mentioned, she sees deliberative democracy in a positivist way. She imagines that there is a group of possible answers or solutions to an 
issue in deliberation, these solution work as hypotheses or guesses of what the real solution is. After being proposed, they are publicly evaluated and the ones that are proved not to be accurate guesses are rejected. In order to reject some guesses on the basis of not being strong enough Landemore must assume some sort of "critical tests" that determine what is valid and what is not. Finally, these tests would determine which hypothesis is the most accurate and discard the others. This understanding of democracy resembles the old positivistic notion of science where science was considered as a means to find the true solution hidden behind reality, like natural laws. Consequently, her view would have to face the same criticism. As Lakatos (1978) explained it, the major problem with this kind of procedure is that in order to falsify a hypothesis it is necessary to determine if the "critical tests" on which we will base our judgement are actually valid or not -whether they can actually be considered falsifiers. It follows from this that the "critical tests" capability to be falsifiers can only be verified by other "critical tests". It is evident that this would lead to an infinite regress of hypothesis and critical tests. In addition, if the critical tests of a hypothesis cannot be known first-hand, we could always modify the hypothesis' feasibility by changing the critical tests that evaluate it.

\section{NON-UNANIMOUS CONSENSUS VIEWS}

Now I would like to explain some epistemic arguments that, contrary to the previous ones, do not require unanimous consensus at the end of the deliberation. Even though they offer stronger justifications for deliberative democracy I will also discuss several objections that still need to be clarified, such as the problem of self-determination or the lack of a feedback mechanism.

One of the exemptions to this general epistemic view could be the argument proposed by Mansbridge et al. (2012: 11). Mansbridge's main claim revolves around the idea that even though we can compare our views to more rational ones it does not follow that we automatically adapt ours to these more rational arguments; on the contrary, we could keep holding our own views irrationally. However, it is true that during deliberation people are "persuaded" to discuss their views and offer supporting reasons publicly. This necessarily leads to being more informed about your own arguments and to acknowledge their weaknesses. Therefore, even though people may want to keep their own "false" views, they still become more rational since, they get more information about these personal views, in order to defend them. What actually matters, then, is not that individual opinions become more rational, but that the process of investigation itself gets "rationalized". Therefore, unanimous consensus is neither possible, nor necessary. The epistemic function of democracy may not be to necessarily make the right choice but rather to produce preferences and decisions that are appropriately informed by facts and reasons. Any result that emerges from the rational process, even if it is through a majority vote, will be more valid because it is more informed and coherent. The epistemic function is fulfilled because deliberative 
democracy is understood as a rational process through which weaknesses are widely "explored".

Mansbridge's theory offers a different view about deliberative democracy. Her main idea is moving the focus of justification from the result of the deliberation to the deliberative process itself. This way, rationality is not necessarily understood in connection to the result but to the process. In other words, the result or solution does not need to be rational, what matters is that the deliberative process is rational itself. Nevertheless, several aspects of her theory require further clarification. First of all, the theory would still face previous criticisms about rationalization made to Landemore's claim, but in this case, they are applied to the process rather than to the result. If the process consists of publicly debating our views, what would happen if there is social influence and the participants cannot fully express their proposals? As I previously explained, in any interaction between people there is influence through non-discursive factors. Social influence can be beneficial, but it can also cause misinformation and self-restraint. This is especially relevant in a deliberative process where the main goal is to publicly share information about different views, so to produce more informed claims. Would social influence make the views less informed and therefore the process less rational itself? Or would it produce more informed but extreme views if the social influence degenerates in polarisation? Mansbridge needs to explain how the argument for a "rationalized" process would avoid the same criticisms as the argument for a "rationalized" result. Otherwise, the problem would remain the same, we have no inherent reason to pursue more informed views. As we previously saw, even the concept of rationality is based on delimitations or falsifiers that make the rationality argument quite unstable.

Another epistemic theory proposed by Christiano (2012) tries to resolve the apparent mismatch between inclusiveness of the collective decision and the quality of a decision based on expert knowledge. He proposes a mixed deliberative system based on the assumption that disagreement is not only inevitable but also valuable and, therefore, it must be preserved. The model includes two parts: the deliberative body or citizens, on one side; and the "theorists" or representatives, on the other. In addition, there is an asymmetry between the functions of both parties. The deliberative body is in charge of setting the goals to be pursued whereas the representatives must find the means to achieve those goals. Common citizens have the most essential functions in the system since they are the driving force. This is the reason why Christiano proposes in the first place that there must be public deliberation in the whole society at any level -i.e. discussion groups or social media. The disagreement after the deliberation must be preserved in "political blocks" so every view, even if minoritarian, is represented. This leads to a representative system where the political parties reflect the views held by different groups of citizens. In order to preserve the value of dissent and, at the same time, make "practical" decisions for the society to advance, a majority rule system is implemented.

While the political aims come from the citizens, the representatives make the actual legislation taking into account these aims. This kind of division of tasks generates a 
common understanding of the reasons for and against policies between the citizens and the representatives. This, in turn, allows the citizens to monitor the representatives' actions and to assess whether they are directed towards achieving the goals they have previously set. The representatives being aware of this control, act truthfully by themselves for fear not to be re-elected. According to Christiano, this kind of system allows for the combination of expert knowledge without disregarding the citizens' different views; hence, it would make deliberative democracy more inclusive and efficient.

Even though Christiano (id.) already places more value on disagreement than his predecessors, his theory can be criticised for the lack of a "feedback mechanism". He proposes a mixed system where both average citizens and experts or representatives play a role. His main idea is that each group complements each other with different functions, this way the decisions made are valid for everyone. The citizens are in charge of several tasks. First, they undergo public deliberation in the whole society, and they express their different views in the form of different political programmes. Next, citizens choose different representatives in a parliament that will work out the "means" to achieve the "aims" stated in the different political programmes. Here we can observe that Christiano (id.) allows for some sort of dissent since citizens do not agree on one unique solution, but they rather propose different political programmes. In addition, this allows citizens and representatives to share overlapping knowledge on the aims and the possible means to achieve them. As a result, the citizens can evaluate the representative's function, which is merely finding the best possible means, and this keeps the representatives "trustful" in their actions. Nevertheless, this theory still falls short in valuing dissent. First, the citizens are only democratically involved in the first part of the process since they do not intervene in the choosing of the means -exclusive for representatives. Second, once the representatives have made a decision -by majority vote- it is assumed that they have acted trustworthily and therefore, it must be accepted as a common decision even if there are still minoritarian groups that disagree. This is the reason why it would be necessary to include a feedback mechanism -between groups and representatives- after a decision is made. Some other aspects that he would need to clarify from his theory are, how exactly does the first deliberation among citizens function and on what platforms -i.e. social media? How exactly does the control of the citizens constrain the representatives' actions?

Dewey proposes another democratic theory from a completely different angle. His experimental view of democracy offers a new explanation of the value of dissent (Shook, 2014). He understands democracy as a deliberative process similar to a thought experiment. He argues that different opinions or disagreements exist at three stages of the democratic process: during the deliberation, at the time of voting and after the decision has been made -as a kind of feedback-. His cooperative thought experiment consists of different influencing parties within the democratic process offering their views and arguments about the best policies to solve our problems (Anderson, 2006). Following this process unfavorable results can be always disconfirmed and changed, even after the decision has been made. Dewey attributes this function to "those publics who suffer the specific problem" (as quoted by Shook, 2014: 69-71). They are in charge of competing, 
always maintaining community goodwill and respect, against other publics for governmental attention to their particular aims. This way, Dewey does not place the value of democracy on the quality of its results but on "polyarchy".

In line with Dahl (2008)'s view, polyarchy is understood as a system of government where opportunities for public contestation are given directly to the general citizenry. In this system, a number of citizens and groups whose interests must be taken into account see their chances for effective participation increase. Hence, it implies that the costs of suppression and unanimity are higher than the costs of tolerating different and opposed opinions. Therefore, an unlikely unanimous consent is not required, since dissent remains valuable throughout the whole process. Dewey, then, sees democracy as a learning process directly linked to education; the goal of which is to achieve "social intelligence", by finding practical solutions that will be in place until better ones are found (as quoted by Shook, 2014: 69-71). This purpose is perfectly described in his statement "We do not desire the immediate feeling but rather the mediated enjoyment of something valuable" (Dewey, 1927). It follows from Dewey's argument that to the extent that democracy was justified in this epistemic way, deliberative democracy could be rated over other political systems. This is due to the fact that, first, it achieves better answers by continuously updating its decisions and, second, it respects disagreement among its participants.

Dewey's theory offers an alternative view to unanimous consensus as necessary for deliberative democracy. He understands dissent as a valuable part of the deliberative process because his main idea is using dissent in democracy as a corrective factor. Dissent has the important task of correcting previous decisions that have been made during deliberation but that have been proved not to work. For this purpose, he counts on the existence of different social and political institutions that work as pressure groups against previous decisions. As a consequence, unanimous consensus is not necessary after deliberation since all the decisions can be replaced in the future based on whether they really function. Nevertheless, he still needs to further explain several aspects of his theory. For example, how does a certain decision receive enough support to be implemented? Or how is it proved that a decision is favorable or unfavorable after its application? Dewey (id.) discusses in "The Public and Its Problems", that consent is achieved in a pluralistic way by voting and majority rule. Previous to making a decision there must be a deliberation where several "hypotheses" are proposed and the strongest one is chosen. But this is only the first stage of the democratic process and he admits that the experts -the political machinery that makes decisions- also have biases that need to be corrected by the citizens whose decisions affect. Therefore, he understands this first stage as a platform for proof and error whose decisions can always be modified by a feedback mechanism that is the essence of democracy. In addition, although he sees voting and majority rule as valid, they still need to be reformed to concentrate the reflexive forces of citizens and not to be a mere arithmetic tool. Nevertheless, Dewey left some important questions unanswered: First, what is the criteria used to choose the most feasible "hypothesis" in the first place? And finally, how does the feedback mechanism actually function? 


\section{FULL-WAY DEMOCRACY}

In this section I will propose an alternative deliberative democratic system that is based on the ideas of several authors as well as on my own reflections. The core of this model is a normative base from which a series of steps are developed in order to achieve a good balance between autonomy and epistemic quality in the deliberative process. It includes three main pillars: first, the moral right of self-determination; second, the value of dissent; and third, the right to contest previous decisions.

One of the most important moral rights that can be attributed to the human nature is the right of self-determination (Kant, 1999: 79-88; Sartre, 1946: 3). This right refers to the basic moral norm that we must be free to decide by ourselves what our life is going to look like and the decisions that we take within it; this is, indeed, an inherent right to any democratic system. Wolff (1998) also arrived at this conclusion from which he proposed that no state is legitimate to impose rules since they neglect this basic right. However, it must not be forgotten that human beings are "political animals" compelled to live in a social context. These two factors lead to an important dilemma: if we are free by nature to decide by ourselves, how can we make collective decisions in a society? Specifically, how could this be possible in a deliberative democratic system where all views are explored, but where a practical decision must be made?

As it has been discussed, one of the possible answers to this question is the system proposed by Landemore (2017) which, nevertheless, leaves one problem unresolved. On the other hand, we can assume that as a result of the right of self-determination any individual involved in collective deliberation would try to influence the collective decision according to their own view. Consequently, no matter what kind of result emerges from deliberation it will be contested by those who still disagree. Therefore, we must assume that no decision generates agreement for the society as a whole. As fatalistic as this assumption may seem, it actually has a lot of hidden value, this is why I will explore this alternative. Therefore, and in line with Dewey (1927), citizens have the right to express their self-determination in the form of disagreement, and disagreement should be manifested through the whole democratic process (Anderson, 2006: 15-17).

This argument can be expressed as the second pillar of the democratic system, namely, the value of dissent. Nevertheless, disagreement needs to be "managed" institutionally to produce practical results. I would like to incorporate some of Christiano's ideas on this matter. Similarly, to Habermas' idea of a "real periphery" that influences the formulation and adoption of policies (Habermas, 1996: 356), Christiano (2012) argues that the first step of a deliberative process must start with an open debate in every sphere of society, including the media, social networks and discussion groups. The second step of this deliberative process would be "managing" the different solutions proposed in order to produce a clear perspective of the disagreement generated during the deliberation. According to him, this could be achieved by the representation of different political programmes that include the aims and interests of the different social groups. In addition, these programmes need to be represented at an institutional level where decisions can be made for the whole society -i.e. an 
assembly. Moreover, from a pluralist view, he argues that different programmes should have similar chances to be represented and to influence the democratic process. That is why Christiano (id.) proposes two institutional arrangements). First, there should be representatives elected by the social groups, who will defend the political programmes in the assembly. Their role would be exclusively limited to find the best means to achieve the aims included in their programmes. Second, the representatives' votes should all have the same value and decisions should be made by majority rule, so to reach the wider possible agreement but also a "practical" and feasible one. According to him, this form of representation could maintain a balance between dissent and epistemic benefits in a deliberative system.

Although Christiano's view gives more importance to dissent, there are three main problems with this system. On the one hand, citizens lose self-determination power, since they only control half of the democratic process -the setting of goals-; while the other half -the application of the means to achieve the goals- is left exclusively to the representatives. On the other hand, his support for majority rule seems to come from the pluralist assumption that it is impossible to overcome disagreement. Therefore, even though disagreement is represented by different political alternatives, at the time of making a definite decision, representatives should take the shortcut of majority rule. In fact, this view would lead us to the "tyranny of the majority" and the blind acceptance of majority policies by the rest of the citizenry, which is evidently a violation of self-determination. Finally, he assumes that the epistemic benefits of the deliberative system are preserved by making a definite decision. However, as Anderson (2006: 13-15) argues, permanently answering questions by decision would not preserve the epistemic benefits but diminish them. The value of dissent resides precisely in its ability to modify the result of deliberation and adapt it to new situations. In order to truly preserve the epistemic benefits, no decision can be definitive.

Following this line of reasoning, it seems necessary to introduce another pillar of the democratic system, "the right to contest previous decisions". As Lafont explains (2019: 182-185), the main goal of deliberative democracy is not to find definitive "best" solutions because at some point social groups within society will disagree with them, therefore no solution can be the best for everyone and forever. The aim of deliberative democracy is "public justification". This principle concerns justifying the benefits of any policy regarding the interests of any social group that contests it. As Anderson (2006) argues, this can only be achieved by a feedback mechanism from the citizenry to the deliberative body. In other words, the deliberative body can make a decision for everyone, but that decision must also be open to contest from any group that disagrees with it. In turn, the deliberative body has the duty to offer justifications that support this group's interests regarding that decision.

In an institutional way, the mechanism needs to be composed of two parts based on the ideas expressed by Lafont (2019). First, there is "judicial contestation"; and second, there is "direct deliberation between groups". Judicial contestation refers to the ruling of the supreme court on a decision previously made by the representative body. Any social group would have the right to resort to judicial contestation and the 
court would, in turn, determine whether a decision made by the representative body goes against the general aims established during the deliberation -i.e. if a double aim is established of economic growth and environmental protection, the Court should examine whether the representatives make a policy for economic growth but investing in fossil fuels. Therefore, the Supreme court would be an organism that assesses whether the policies that have been already made fulfil the majoritarian aims of the assembly. If still unsatisfied, any social group would have the opportunity to negotiate directly with the majoritarian deliberative body to obtain favorable justifications in their support. Finally, if no agreement is reached, any social group could call for a public modification of a decision through a referendum. Of course, this system is not made for every group to agree on everything at any time, indeed, some controversial policies may take more time to be settled. Any other social group could start the feedback mechanism again keeping disagreement active. This mechanism of decision-making and feedback respects disagreement through the whole democratic process while it truly keeps the epistemic benefits of decisions. This is due to the fact that policies are not definitive but continuously updated by different social groups whose needs evolve in a changing political context.

\section{CONCLUSIONS}

In this essay I have argued that the current epistemic view of deliberative democracy falls short of finding out what makes deliberative democracy better than other political systems. The main reason is that the epistemic view of deliberative democracy fails to identify the uniqueness of deliberation itself. This uniqueness refers to the democratic quality, which refers to the capability of deliberation to identify and adapt to citizens' needs. I have argued that the epistemic view is not enough to account for this capability. This is why I propose the creation of a feedback mechanism from citizens to institutions that allows for dynamic policy making and improves the solutions to the challenges we face. As I previously explained, this aim comprises three factors: the respect of self-determination, the value of dissent and the right to contest previous decisions.

I started this article with some remarks on the value of deliberative democracy as an interesting solution to the objections against other democratic systems such as representative or direct democracy. However, I argued that the current views about deliberative democracy overly focus on the epistemic qualities of the decision, neglecting other essential democratic characteristics.

In this sense, Landemore's theory (2017) is the one that poses more problems. Although it can be understood that she argues for a certain degree of self-determination within the deliberative body, it is evident that citizens' self-determination can never be equal to that of a deliberative body. She wrongly assumes that equal chances of participation mean equal self-determination. There is no value of dissent since decisions are accepted by unanimous consensus both in the deliberative body and in 
society. Previous decisions cannot be contested either, since it would be contradictory to demand unanimous consensus on objective decisions that will be changed afterwards.

As we have seen, Christiano (2012) proposes a system more based on individuality, where self-determination is valued but only to certain extent. Citizens vote to achieve different aims in their society, but the means to achieve these aims can only be found by the representatives. Dissent and decision changes are also important since, in this system, bargaining between different perspectives is necessary to make policies. Nevertheless, it tends to majority rule by coalition building, and therefore, it ignores minorities.

Dewey (1929) offers a similar response, but he increases citizens' power to participate. Individuals and groups have more space to interact with the institutions and shape policies. His system is dynamic and definitely involves a feedback mechanism that is updated throughout time; this way, no policy is immune to change. Nevertheless, and paradoxically, it can also disregard minorities if it relies excessively on majority rule.

According to my knowledge on this subject, Lafont (2019) is the author that comes closer to the ideal model. By defending deliberation as justification, she covers a great deal of the three aspects. Self-determination as well as dissent are respected at every stage of the policymaking, since the value of deliberation is to justify any policy according to the needs of all the groups affected by it. Even though the epistemic benefits of Lafont's system are only temporal, they are also more flexible since new perspectives are added to previous policies when the contextual factors change.

TABLE I.

AUtHORs' THEORIES AND THEIR COMPATIBILITY WITH THE FEEDBACK MECHANISM

\begin{tabular}{lcccc}
\hline Pillars of the feedback mechanism & Landemore & Christiano & Dewey & Lafont \\
\hline Right to self-determination & - & $\sqrt{ }$ & $\sqrt{ }$ & $\sqrt{ }$ \\
\hline Value of dissent & $\times$ & $\sqrt{ }$ & $\sqrt{ }$ & $\sqrt{ }$ \\
\hline Right to contest previous decisions & $\times$ & $\times$ & - & - \\
\hline
\end{tabular}

Source: Own elaboration.

In this sense, the first step to improve our current representative systems is by empowering citizens to participate in the political activity and the principles that define their society. Lafont takes this debate specifically to the judicial arena (ibid.: 191-234). She starts by explaining that there is a major divide in the literature regarding constitutional review and the degree of citizen's implication. The main gap is between those who argue that constitutional review should be carried out by judicial review and those who see judicial review as an "expertocratic" shortcut that undermines the democratic values. She aligns herself with the first option.

The second notion criticises judicial review on three grounds. Firstly, judicial review is undemocratic since it places experts' opinions -for example Supreme Court 
judges- about how the constitution should be interpreted over those of normal citizens. Secondly, judicial review only allows private citizens to legally complain against a policy based on their own interest, but with no political aim that involves the whole community. Thirdly, judicial review gives some citizens an unpolitical advantage to obtain concessions from those citizens that have voted for the majority and given them the right to legislate.

Lafont dismisses all these objections (id.). Firstly, she argues that judicial review is not an "expertocratic" shortcut, since it is citizens who contest policies through the courts, not judges who act on their own to impede citizens from legislating. In this sense, it is not "judges against the people" as some critics portray it, but "citizens against citizens". Judges are also necessary for another reason, contestations by citizens from minority groups cannot be evaluated by the remaining majority since they would evaluate them on the base of contradictory interests and the minority may always be ignored. Secondly, while Lafont assumes that citizens come to court mainly based on their own interests, the use of the court itself turns those interests into political aims. For her, judicial review functions as a platform to structure the political discourse about principles that dictate the way we should treat each other. In other words, judicial review allows citizens to escalate the debate from a private issue to a principles issue. Public political debates may have started long ago in the public sphere, but they do not become institutionalised until they go to the court. Finally, judicial review does not give an advantage to minoritarian groups in the sense of obtaining concessions. It is rather a tool that can be used only to defend basic rights, whereas the majoritarian group can create any policy it wants due to its electoral power in the legislature. For all these reasons, she concludes that the judicial review is purely democratic. The solution she proposes to increase citizens' participation is that judicial institutions should be encouraged both at local and supranational levels. This would make possible for citizens who are directly affected by policies to contest them.

Even though I agree with most of Lafont's arguments, in my view this is not the proper way to create a feedback mechanism that encourages citizens participation. First of all, one thing is that judicial review is available to all citizens and, a very different one is that they are equally able to use it. Creating the tool is not enough, we have to put it on everyone's hands. In fact, a contestation tool that can only be used by certain groups of citizens or organisations -i.e. powerful corporations- is not democratic at all. Both information and resources are of major importance for this matter. The sectors of the population that have more information, time and resources make more use of legal contestation than some others, even though they might be all equally affected by the legislature policies. If we are looking for fairness in the use of this tool, we should promote that the groups directly affected by the policy in question can resort to legal contestation as easily as any other group. An answer to this issue is perhaps the creation of a common budget for citizens contestation and participation included in the obligations of any legislature. In addition to this budget, institutions might be needed with the aim of compensating sectors of the population for the lack of resources, time and information in policy-making and judicial review. 
Secondly, a section of Lafont's argument justifies the necessity of judges since, if groups of citizens were to judge each other, electoral politics would always give an advantage to the opinions of those aligned with the majority. As a consequence, minoritarian contestations, even if right, would be dismissed. The presence of judges in the system is essential; so that any contestation can be evaluated considering everyone's interests. However, she seems to forget that judges are also affected by electoral politics, since they belong to the citizenry too. In fact, the political and the justice systems are often intertwined, what does not only affect the result of judicial review but also the very admission or rejection of the cases in Courts (Hernández, 2014). In other words, the political influence on the justice system can block what Lafont calls the escalation of an issue from a political debate to a principles debate.

As a final resource, when citizens fail to escalate the issue through judicial review, they may still mobilize and create pressure to force the legislature to accept a public consultation. In this ideal case, citizens get to successfully escalate the issue to a principles debate with the rest of the citizenry, they ask other citizens to act as judges and vote. This procedure is perfectly democratic, but there are several problems with the way Lafont describes it. Judicial review serves as platform where to structure and escalate debates. However, if we relied on citizens mobilisation as the ultimate platform to escalate an issue, why should we waste our resources using the judicial review in first place? In other words, if the legislature could call for a referendum anyways, it would be more logical to put pressure directly on the government by escalating the debate in the public sphere in the form of social mobilisation. Secondly, this kind of strategy does not function as Lafont depicts it. On the one hand, even if most mobilisations are about important issues, they do not end up in public consultations. On the other hand, many of the modifications of our essential principles that should take place in the form of public consultations do not do so. A typical example is the amendment of the article 135 of the Spanish constitution during the economic crisis (Benitez, 2012). This mismanagement of citizens participation occurs because there is no direct mechanism that connects the citizens with the parliament in the proposal and coordination of the public agenda. In the previously described system, the parliament has the ultimate power to escalate issues to principles debates about fundamental rights; in other words, the importance given to minoritarian contestations are left to the will of the parliament alone.

This is not the optimal situation for the feedback mechanism that I intend. As it has just been argued, the ultimate power to consider the status of an issue is left to the Parliament, that can use it in an opportunistic way. For example, if the judicial review determines that certain policy is unconstitutional because it violates the basic rights of a minority, the majoritarian legislature can organise a popular consultation and amend the constitution afterwards. I propose that this error should be corrected by a mechanism that legally binds the legislature to organise popular consultations exclusively and every time they are demanded. Regardless of the result of judicial review, if the minority is still convinced that certain debate should involve the whole citizenry, they must be able to force Parliament to propose a public consultation as the ultimate resource. At the same time, this mechanism limits the extent to which the parliament 
can use public consultations opportunistically or modify constitutional rights without consulting the citizens first, since such modifications could only be made through a citizens' initiative and with the citizens' support.

Arguably, a downside of this mechanism is that it would slow down the procedures of our current democracies, and it would need a great deal of coordination. The debate about its efficiency or the way it can be carried out goes beyond the scope of this article. My proposal does not mean that judicial review should disappear; on the contrary, judicial review is one of the pillars of this mechanism. However, it acknowledges that judicial review is only one of the many platforms where an issue can be escalated, and it is not the ultimate one. Leaving aside its practical construction, this mechanism fulfils its theoretical purpose of creating a direct link from the citizens to the legislature as a form of feedback that respects the three pillars of self-determination, the value of dissent and the right to contest previous decisions.

The main themes discussed in this article have been relevant to debates as diverse as the prioritization of the resettlement of refugees based on group criteria (Cherem, 2020) or the historical reassessment of political systems such as that of the republic of Genoa and its social impact (Buchstein, 2019). I hope that my discussion on this dilema has shown the strengths and weaknesses that any democratic arrangement can face. I also expect to have demonstrated that the fear to reconcile both citizens' disagreement and epistemic benefits in a deliberative process is unfounded since it is precisely disagreement what generates epistemic benefits in a democracy.

\section{References}

Anderson, Elizabeth. 2006. "The epistemology of democracy", Episteme, 3 (1-2): 8-22. Available at: https://doi.org/10.3366/epi.2006.3.1-2.8.

Bächtiger, André, John S. Dryzek, Jane Mansbridge and Mark E. Warren. 2018. "Deliberative democracy: an introduction", in The Oxford handbook of deliberative democracy. Oxford: Oxford University Press. Available at: https://doi. org/10.1093/oxfordhb/9780198747369.001.0001.

Benítez, Octavio S. 2012. "La Constitución domesticada: algunas reflexiones críticas sobre la reforma del artículo 135 CE", Teoría y Realidad Constitucional, 29: 409-432. Available at: https://doi.org/10.5944/trc.29.2012.6998.

Bessette, Joseph. 1994. The Mild Voice of Reason: Deliberative Democracy and American National Government. Chicago: University of Chicago Press.

Buchstein, Hubertus. 2019."Democracy and lottery: Revisited", Constellations, 26 (3): 361-377. Available at: https://doi.org/10.1111/1467-8675.12429.

Cherem, Max G. 2020. "May states select among refugees?", Ethics and Global Politics, 13 (1): 33-49. Available at: https://doi.org/10.1080/16544951.2020.1735018.

Christiano, Thomas. 2012. "Rational deliberation among experts and citizens", in John Parkinson and Jane Masbridge (eds.), Deliberative systems: Deliberative democracy at the large scale. Cambridge: Cambridge University Press. 
Cortina, Adela. 1993. Ética aplicada y democracia radical. Madrid: Tecnos.

Dahl, Robert A. 2008. Polyarchy: Participation and opposition. New Haven: Yale University Press.

Dewey, John. 1927. The Public and Its Problems. Ohio: Swallow Press.

Dryzek, John. 2000. Deliberative democracy and beyond: Liberals, critics, contestations. Oxford: Oxford University Press.

Estlund, David and Hélène Landemore. 2018. "The epistemic value of democratic deliberation”, in Andre Bächtiger, John S. Dryzek, Jane Mansbridge and Mark Warren (eds.), The Oxford handbook of deliberative democracy. Oxford: Oxford University Press. Available at: https://doi.org/10.1093/oxfordhb/9780198747369.013.26.

Fishkin, James S. 2018. Democracy when the people are thinking: Revitalizing our politics through public deliberation. Oxford: Oxford University Press. Available at: https://doi.org/10.1093/oso/9780198820291.001.0001.

Fishkin, James S. and Robert C. Luskin. 2005. "Experimenting with a democratic ideal: Deliberative polling and public opinion", Acta politica, 40 (3): 284-294. Available at: https://doi.org/10.1057/palgrave.ap.5500121.

Habermas, Jürgen. 1996. Between facts and norms. Massachusetts: MIT Press. Available at: https://doi.org/10.7551/mitpress/1564.001.0001.

Hernández, Diego Í. 2014. "La contrarreforma del Consejo General del Poder Judicial", Teoría y Realidad Constitucional, 34: 333-348. Available at: https://doi. org/10.5944/trc.34.2014.14098.

Hong, Lu and Scott E. Page. (2004). "Groups of diverse problem solvers can outperform groups of high-ability problem solvers", Proceedings of the National Academy of Sciences, 101 (46): 16385-16389. Available at: https://doi.org/10.1073/ pnas.0403723101.

Kant, Immanuel. 1999. Critique of practical reason. Cambridge: Cambridge University Press.

Kobach, Kris W. 1993. The Referendum: Direct Democracy in Switzerland. Aldershot: Dartmouth Publishing Company.

Lafont, Cristina. 2019. Democracy without Shortcuts: A Participatory Conception of Deliberative Democracy. Oxford: Oxford University Press. Available at: https:// doi.org/10.1093/oso/9780198848189.001.0001.

Lakatos, Imre. 1978, "The Methodology of Scientific Research Programmes", Philosophical papers, 1. Available at: https://doi.org/10.1017/CBO9780511621123.

Landemore, Hélène. 2017. Democratic reason: Politics, collective intelligence, and the rule of the many. Princeton: Princeton University Press.

Mansbridge, Jane, James Bohman, Simone Chambers, Thomas Christiano, Archon Fung, John Parkinson, Dennis F. Thompson and Mark E. Warren. 2012. "A systemic approach to deliberative democracy", in John Parkinson and Jane Mansbridge (eds.), Deliberative Systems. Deliberative Democracy at the Large Scale. Cambridge: Cambridge University Press.

Morlino, Leonardo. 2014. La calidad de las democracias en América Latina. Informe para IDEA Internacional. San José: IDEA Internacional. 
Red de Conocimientos Electorales. (n. d.). El significado de la democracia. Available at: https://aceproject.org/main/espanol/ve/vec05b01.htm.

Sartre, Jean-Paul. 1946. Existentialism and Humanism. Translated by Carol Macomber. New Haven: Yale University Press.

Shook, John. 2014. Dewey's social philosophy: Democracy as education. New York: Springer.

Wolff, Robert Paul. 1998. In defense of anarchism. California: University of California Press. Available at: https://doi.org/10.1525/9780520353916.

Presented for evaluation: October 16th, 2020.

Accepted for publication: June 18th, 2021.

\section{OSVALDO GONZÁLEZ-REYES}

osvaldogreyes7@gmail.com

Graduado en Psicología y Filosofía por la Universidad de Groningen y máster en Ciencia Política por la Universidad Autónoma de Madrid (UAM). Se ha especializado en las áreas de psicología social y teoría política y sus intereses de investigación incluyen los procesos de influencia normativa y grupal, así como las estructuras de toma de decisiones. Actualmente desarrolla sus actividades en el Madrid Institute for Advanced Study (UAM) sobre temas de innovación en el sector público. 